\title{
Conversion of isopropyl alcohol over Ru and Pd loaded N-doped carbon nanotubes
}

\author{
Anas Benyounes a,b, Mohamed Kacimi b,*, Mahfoud Ziyad b,c, Philippe Serp a,\# \\ a Laboratory of Coordination Chemistry UPR CNRS 8241, ENSIACET Group, Toulouse University, 4 allée Emile Monso - CS 44362, Toulouse Cedex 4, France \\ b Laboratory of Physical Chemistry of Materials, Catalysis and Environment (URAC26), Department of Chemistry, Faculty of Science, University of \\ Mohammed V-Agdal, BP1014 Rabat, Morocco \\ ${ }^{c}$ Hassan II Academy of Science and Technology, Rabat, Morocco
}

\section{A R T I C L E I N F O}

\section{Article history:}

Received 31 March 2014

Accepted 25 April 2014

Published 20 June 2014

\section{Keywords:}

Ruthenium

Palladium

Nitrogen-doped carbon nanotubes

Isopropyl alcohol

Decomposition

Acetone

\begin{abstract}
A B S T R A C T
Ru and Pd (2 wt\%) loaded on pure and on N-doped carbon nanotubes (N-CNTs) were prepared and tested using the isopropyl alcohol decomposition reaction as probe reaction. The presence of nitrogen functionalities (pyridinic, pyrrolic, and quaternary nitrogen) on the nitrogen doped support induced a higher metal dispersion: Pd/N-CNT (1.8 nm) < Pd/CNT (4.9 nm), and Ru/N-CNT (2.4 nm) $<\mathrm{Ru} / \mathrm{CNT}(3.0 \mathrm{~nm})$. The catalytic activity of the supports was determined first. Isopropyl alcohol conversion produces acetone on CNTs while on N-CNTs it led to both dehydration and dehydrogenation products. At $210^{\circ} \mathrm{C}$ and in the presence of air, the isopropyl alcohol conversion was higher on the N-CNTs (25\%) than on the CNTs (11\%). The Pd loaded catalysts were more active and more selective than the Ru ones. At $115^{\circ} \mathrm{C}$, the Pd catalysts were $100 \%$ selective towards acetone for a conversion of $100 \%$, whereas the Ru catalysts led to dehydration and dehydrogenation products. The nitrogen doping induced the appearance of redox properties when oxygen is present in the reaction mixture.
\end{abstract}

(C) 2014, Dalian Institute of Chemical Physics, Chinese Academy of Sciences. Published by Elsevier B.V. All rights reserved.

\section{Introduction}

Conversion of alcohols by dehydrogenation or dehydration is an interesting process, commonly used to investigate acid/base features of catalysts surface that are either oxide-based [1-3], or carbon-based [4-8]. Several studies have been dedicated to the research of correlations between the used techniques to characterize the acid-base properties of catalysts (adsorption of bases or acids, TPD...) and the conversion of alcohols, including isopropyl alcohol (IPA) [9-11]. In general, alcohols undergo dehydration to olefins and ethers mainly over acidic sites and dehydrogenation to aldehydes or ketones over basic or redox sites. These transformations occur through dif- ferent mechanisms depending on the nature of the used materials [12]. The dehydration reaction of primary and secondary alcohols follows mostly a bimolecular elimination E2 concerted mechanism, which involves acid and sometimes basic sites of the catalyst leading to olefin and ether production. However, alcohol dehydration can also proceed through the unimolecular elimination mechanism E1cB, which implicates carbanion intermediates on solids that possess acid/base sites with high strength. On the other hand, the dehydrogenation reaction can occur over strong basic solid catalysts through a mechanism that involves the same intermediate carbanion to give olefins, albeit in this case, the ketone is produced by $\alpha$-hydrogen abstraction. Another alternative mechanism for dehydrogenation

\footnotetext{
* Corresponding author. Fax: +212-537775440; E-mail: m_kacimi2000@yahoo.fr

* Corresponding author. Fax: +33-534323596; E-mail: philippe.serp@ensiacet.fr

DOI: 10.1016/S1872-2067(14)60121-2 | http://www.sciencedirect.com/science/journal/18722067 | Chin. J. Catal., Vol. 35, No. 6, June 2014
} 
is an oxidative process, in which redox centers and molecular or lattice oxygen are required. When converting IPA on acidic or basic solids, three parallel reactions can occur and the possible products can be propene, di-isopropyl ether, and acetone. The intramolecular dehydration of IPA to propene characterizes the surface acidity or the catalyst. The dehydrogenation reaction producing acetone characterizes the basic properties of the catalyst. The presence of redox sites can also promote dehydrogenation of IPA in the presence of oxidants [13]. The third reaction, which rarely occurs and depends on the strength of the sites, is the intermolecular dehydration of two molecules of alcohol, yields di-isopropyl ether. Dehydrogenation of IPA is also considered as an excellent test for metal supported catalysts. Indeed, decomposition of alcohols on various types of catalysts via dehydration or via dehydrogenation is an interesting process, because of its application to produce alkenes and carbonyl compounds such as formaldehyde or acetone. Several studies on the interaction of metallic or bimetallic catalysts with IPA were published [4,14-19]. In most of these investigations, IPA-metal interaction proceeds via the formation of isopropoxide (alkoxide) intermediate. This result was confirmed by a variety of surface characterization techniques. Therefore, isopropoxide species lead to the formation of acetone [20].

The acidity and basicity of carbon materials are two factors that impact their activity and selectivity, not only in typical acid-base reactions but also in many other, including redox transformations. In recent studies it was shown that N-doped nanostructured carbon materials exhibited enhanced anion exchange properties and a catalytic activity in redox reactions. So far, it has been demonstrated that the presence of nitrogen can be a key parameter that improves the catalytic performance of carbon materials [21-23].

In this study we reported on the synthesis and characterization of Ru and Pd catalysts supported on pristine and N-doped carbon nanotubes (CNTs). The catalytic features of the supports and their modification by the $\mathrm{Pd}$ and $\mathrm{Ru}$ incorporation were investigated using IPA conversion as probe reaction.

\section{Experimental}

\subsection{CNT synthesis}

The CNTs were synthesized by catalytic-CVD in a fluidized bed reactor using ethylene as carbon source and acetonitrile/ $\mathrm{N}_{2}$ as carbon/nitrogen source. The Fe catalyst supported on $\mathrm{Al}_{2} \mathrm{O}_{3}$ was pre-reduced under hydrogen during $30 \mathrm{~min}$ at $650{ }^{\circ} \mathrm{C}$. A typical experiment was carried out initially with ethylene $\left(600 \mathrm{~mL} \mathrm{~min}^{-1}\right)$ for $30 \mathrm{~min}$ to produce CNTs. N-CNTs were produced from acetonitrile/ $\mathrm{N}_{2}$ for $30 \mathrm{~min}$. The produced carbon nanotubes were purified by aqueous solution of $\mathrm{H}_{2} \mathrm{SO}_{4}$ (50 vol\%) under reflux for $3 \mathrm{~h}$ to facilitate the total dissolution of alumina and partial elimination of exposed iron particles contained in the nanotubes.

\section{2. $R u / C N T$ and $P d / C N T$ catalyst preparation}

In order to incorporate $2 \mathrm{wt} \%$ of $\mathrm{Ru}$ or Pd in the CNTs, the desired amounts of $\mathrm{Pd}\left(\mathrm{NO}_{3}\right)_{2} \cdot x \mathrm{H}_{2} \mathrm{O}$ and $\mathrm{Ru}(\mathrm{NO})\left(\mathrm{NO}_{3}\right)_{x}(\mathrm{OH})_{y}$ were added to an acetone solution $(20 \mathrm{~mL})$ containing $0.5 \mathrm{~g}$ of nanotubes. After stirring overnight at ambient temperature, the catalysts were filtered, washed with acetone and dried in an oven at $120^{\circ} \mathrm{C}$. The catalysts were then reduced at $300{ }^{\circ} \mathrm{C}$ for 2 hours in a horizontal oven under an $\mathrm{Ar}-\mathrm{H}_{2}$ flow (20 vol\% $\mathrm{H}_{2}$ ).

\subsection{Characterization}

The hybrid nanostructures were characterized using transmission electronic microscopy (TEM-FEI Tecnai-G2-20-FEI 2006, at $200 \mathrm{kV}$ ), CHN Perkin-Elmer elemental analyzer, Raman spectroscopy (SENTERRA at $=633 \mathrm{~nm}$ ), and TG/DTA Shimadzu, under air $\left(10^{\circ} \mathrm{C} \mathrm{min}^{-1}\right.$ to $\left.900{ }^{\circ} \mathrm{C}\right)$. Particle size distribution was determined using the Image J software on at least 300 nanoparticles. The textural characterization (BET surface areas, $S_{\text {BET }}$ ) of the materials was based on the $\mathrm{N}_{2}$ adsorption isotherms determined at $-196{ }^{\circ} \mathrm{C}$ with a Quantachrome Autosorb apparatus. EELS measurements for the K-edge absorption for $\mathrm{C}$ and $\mathrm{N}$ were used to estimate the stoichiometry of the nanotubes. EELS experiments have been performed with a Philips CM200 microscope. The samples were also analyzed by X-ray photoelectron spectroscopy (XPS) using a VG Escalab MKII spectrophotometer, which operated with a nonmonochromatized $\mathrm{Mg} K_{\alpha}$ source (1253.6 eV).

\subsection{Catalytic test}

The activities of the catalysts were measured by the decomposition of IPA performed at atmospheric pressures, in a pyrex fixed bed microreactor placed inside a vertical furnace. Prior to the tests, the catalyst $(0.1 \mathrm{~g})$ was treated at $400{ }^{\circ} \mathrm{C}$ under $60 \mathrm{~mL} \mathrm{~min}^{-1}$ of $\mathrm{N}_{2}$ then cooled to the reaction temperature. IPA at a partial pressure of $1.2 \mathrm{kPa}$ was supplied to the reactor by a saturator fed with $\mathrm{N}_{2}$ or air at a total flow rate of 60 $\mathrm{mL} \mathrm{min}^{-1}$. Reaction products were analyzed by on-line gas chromatography using an ATI Unicam 610 chromatograph equipped with a flame ionization detector and a $4 \mathrm{~m}$ column packed with Chromosorb PAW coated with 15\% of carbowax 1500 for 2-propanol, acetone, propene and ether separation, and the other one Shimadzu GC-8A equipped with a silica gel column and TCD detector for $\mathrm{CO}_{x}$ analyses. The reaction features were defined as follows:

$$
\begin{aligned}
& \text { Conversion }=\frac{n\left(\mathrm{IPA}_{\text {in }}\right)-n\left(\mathrm{IPA}_{\text {out }}\right)}{n\left(\mathrm{IPA}_{\text {in }}\right)} \times 100 \\
& \text { Product yield }=\frac{\text { Fraction of IPA converted to product }}{\mathrm{IPA}_{\text {in }}} \times 100 \\
& \text { Product selectity }=\frac{\text { Product yield }}{\text { Conversion }} \times 100
\end{aligned}
$$

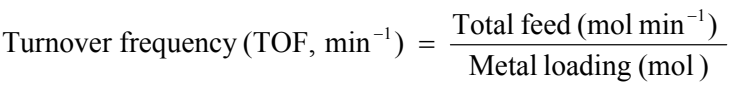

$$
\begin{aligned}
& x \text { conversion }
\end{aligned}
$$

\section{Results and discussion}

\subsection{Material synthesis and characterization}


The CNTs were synthesized by CVD using ethylene as carbon source (CNTs) and acetonitrile as $\mathrm{C} / \mathrm{N}$ source (N-CNTs). TEM images of the CNT sample showed the presence of very regular multi-walled CNTs with an average external diameter of ca. $12 \mathrm{~nm}$ (Fig. 1(a)). On the other hand, the sample N-CNTs showed the classical "bamboo-like" structure of N-doped CNTs, and larger diameters of ca. $18 \mathrm{~nm}$ (Fig. 1(b)). N-doped nanotube structure exhibited several defects and tended to form arches in the graphene layers as intern caps due to the shorter length of the $\mathrm{N}-\mathrm{C}$ bonds [24]. Nitrogen is preferentially incorporated inside the transversal bended arches in the CNT structure, whereas the curled arches have a relatively low nitrogen incorporation [25]; and the $\mathrm{N}$ atoms are distributed throughout the CNT structure.

The introduction of nitrogen also induces a significant decrease of the yield of the reaction (Table 1), presumably due to different growth mechanisms [26]. The production of such defective CNTs has already been reported, when acetonitrile was used as carbon and nitrogen source $[27,28]$. The $\mathrm{N}$ content in each sample was determined by elemental analyses and the results are shown in Table 1.

The sample CNTs showed $94.6 \%$ carbon and no nitrogen nor hydrogen. The remaining $5.4 \%$ is likely related to some oxygen and mainly encapsulated iron particles present inside the CNTs. On the other hand, for the N-CNTs sample the N content increased to $6.1 \%$. These results were confirmed by EELS analyses (Fig. 1). A nitrogen content of $6.1 \%$ corresponds to a $\mathrm{C} / \mathrm{N}$ bulk atomic ratio of $c a$. 15 in the CNT composition. On the other hand, XPS analyses of the sample N-CNTs (Fig. 2) showed a 96/4 C/N ratio suggesting a lower $\mathrm{N}$ concentration on the surface. At least three types of nitrogen species are found in $\mathrm{N}$-doped CNTs: pyridinic, pyrrolic, $\mathrm{N}$-oxide, and quaternary nitrogen. Nitrogen peak deconvolution indicated the presence
Table 1

Yield, BET surface area, and C and N content for the produced CNTs.

\begin{tabular}{lcccccccc}
\hline Sample & $\begin{array}{c}\text { Yield } \\
\left(\mathrm{gC}_{\mathrm{cat}^{-1}}{ }^{-1}\right)\end{array}$ & $\begin{array}{c}\mathrm{d}_{002} \\
(\mathrm{~nm})\end{array}$ & $\begin{array}{c}d_{\mathrm{Ext}} \\
(\mathrm{nm})\end{array}$ & $\begin{array}{c}S_{\mathrm{BET}} \\
\left(\mathrm{m}^{2} \mathrm{~g}^{-1}\right)\end{array}$ & $\begin{array}{c}\mathrm{C} \\
(\mathrm{wt} \%)\end{array}$ & $\begin{array}{c}\mathrm{N} \\
(\mathrm{wt} \%)\end{array}$ & $I_{\mathrm{D}} / I_{\mathrm{G}}$ & $I_{\mathrm{G}^{\prime}} / I_{\mathrm{G}}$ \\
\hline CNTs & 4.8 & 0.343 & 12 & 258 & 94.6 & 0 & 0.6 & 0.2 \\
N-CNTs & 1.1 & 0.336 & 18 & 194 & 76.9 & 6.1 & 0.8 & 0.1 \\
\hline
\end{tabular}
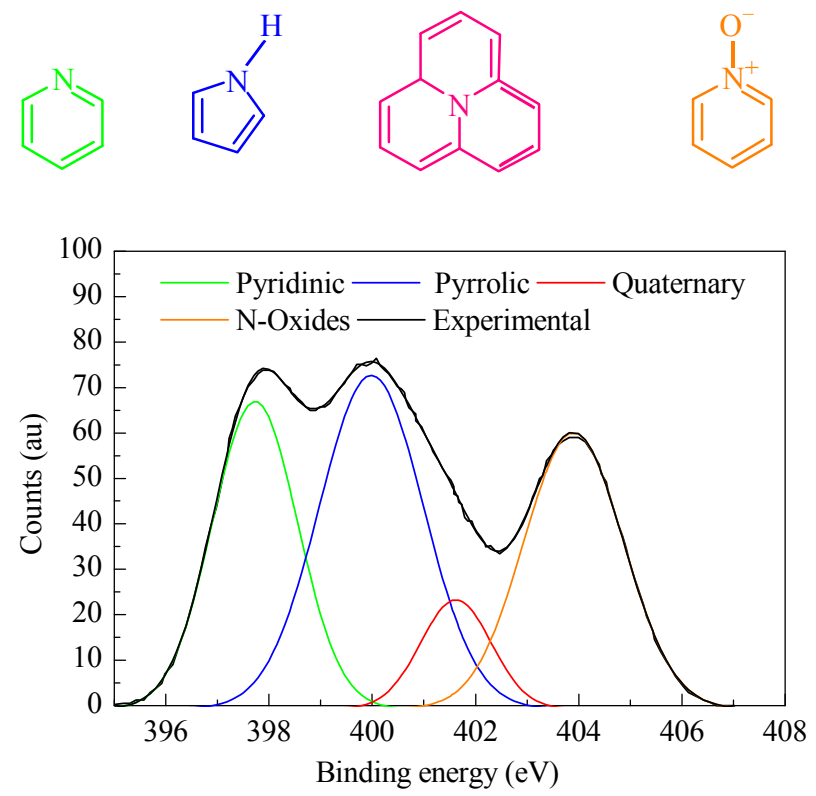

Fig. 2. $\mathrm{N} 1 s \mathrm{XPS}$ spectrum of N-CNTs.

of $29 \%$ pyridinic nitrogen, $31 \%$ of pyrrolic nitrogen, $12 \%$ of quaternary nitrogen, and $28 \%$ of nitrogen oxides.

XRD analyses of the samples showed a slight decrease of the do02 distance with the nitrogen content, i.e. from $3.43 \AA$ for CNTs to $3.36 \AA$ for N-CNTs. Such a phenomenon has already
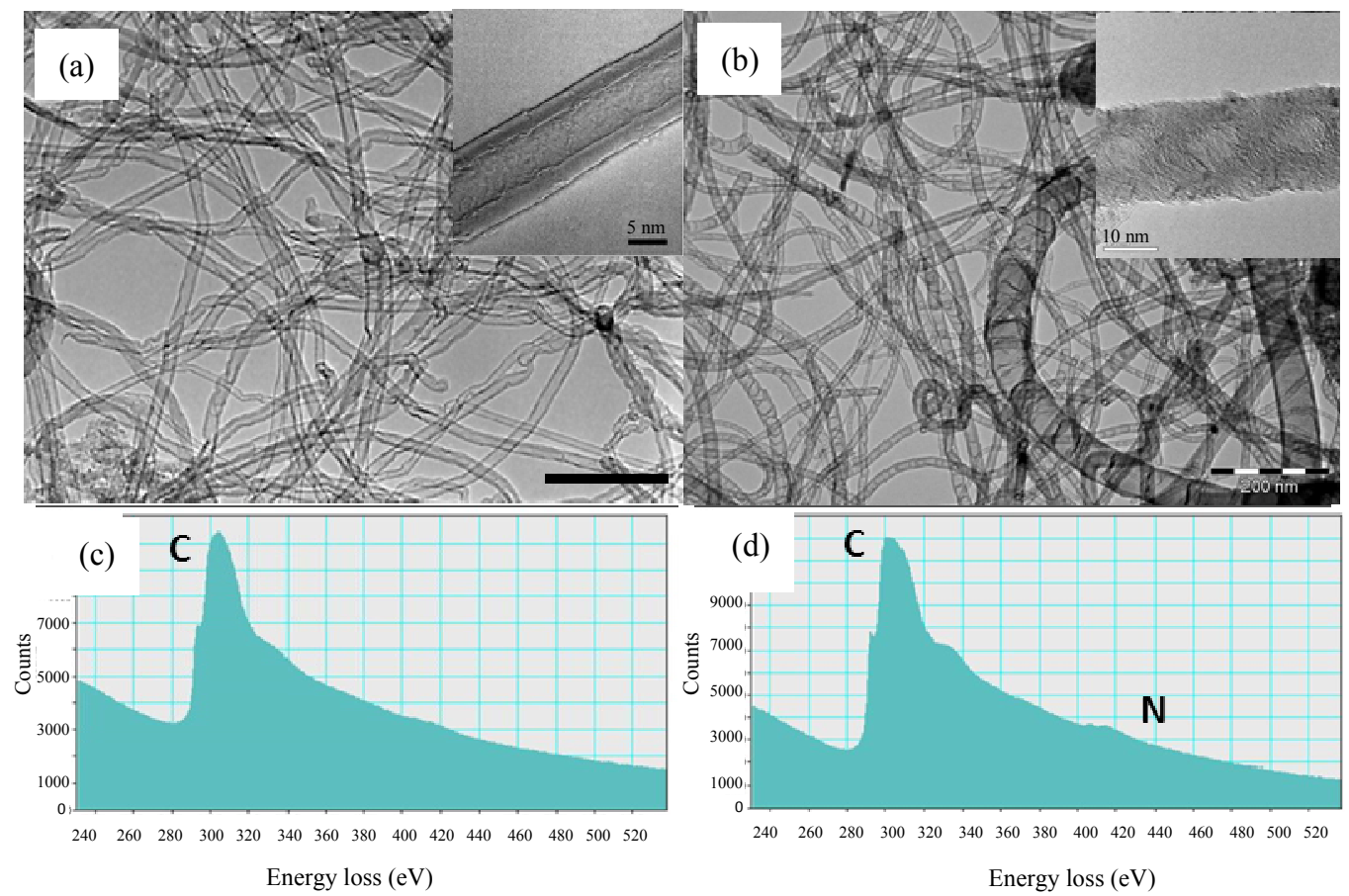

Fig. 1. TEM images of CNTs (a), N-CNTs (b), EELS spectrum of CNTs (c), and EELS spectrum of N-CNTs (d). 
been reported for $\mathrm{N}$-doped carbon nanostructures [29]. TGA/DTA analyses under air (not shown here) for CNTs displayed a well-defined peak near $600{ }^{\circ} \mathrm{C}$ related to the oxidation of a well-organized carbon structure. On the other hand, the sample N-CNTs showed an oxidation temperature of $c a .465^{\circ} \mathrm{C}$, which suggests the presence of more defective and reactive carbon. BET measurements showed that the surface areas tended to be larger for CNTs compared to the samples N-CNTs (Table 1), in agreement with the larger measured external mean diameter for the nitrogen rich samples. Raman spectra (not displayed) showed the presence of one strong first order peak at $\sim 1560 \mathrm{~cm}^{-1}$ (G-band) and three second order features at $\sim 1330$ (D-band), $\sim 2700$ (G'-band), and $\sim 2940 \mathrm{~cm}^{-1}$, typical of multi-walled CNTs [30]. The second-order peak around 2940 $\mathrm{cm}^{-1}$ is a combination of the D and G bands [31]. The ratio of D to $G$ band intensities can be used to evaluate defects in the CNTs structures. The influence of nitrogen in the CNTs can also be evaluated by the ratio of $\mathrm{G}^{\prime}$ and $\mathrm{G}$ intensities (Table 1 ). It can be observed two effects as N content in the CNTs increases: the $I_{\mathrm{D}} / I_{\mathrm{G}}$ ratio increase and the relative intensity of the $\mathrm{G}^{\prime}$ band decreases. These results are consistent with the presence of $\mathrm{N}$ in the CNT structure, i.e. there is an increased of defects in the CNT structure in the presence of nitrogen [30-32].

We investigated the potential use of these CNTs as support for $\mathrm{Ru}$ or Pd catalysts. Indeed, high metal dispersions have regularly been reached on N-doped CNTs [33-36]. A series of Ru and $\mathrm{Pd}$ catalysts were prepared by wetness impregnation from $\left[\mathrm{Ru}(\mathrm{NO})\left(\mathrm{NO}_{3}\right)_{3}\right]$ and $\left[\mathrm{Pd}\left(\mathrm{NO}_{3}\right)_{2}\left(\mathrm{H}_{2} \mathrm{O}\right)_{2}\right]$, respectively. TEM micrographs and particle size distributions are shown on Fig. 3. It is clear that the metal dispersion increases with the $\mathrm{N}$ content in the CNTs. For the Pd catalysts, the mean Pd particle size was Pd/CNT $(4.9 \mathrm{~nm})>\mathrm{Pd} / \mathrm{N}-\mathrm{CNT}(1.8 \mathrm{~nm})$. The same tendency has been observed for the $\mathrm{Ru}$ catalysts, for which the mean particle size was $3 \mathrm{~nm}(\mathrm{Ru} / \mathrm{CNT})>2.4 \mathrm{~nm}(\mathrm{Ru} / \mathrm{N}-\mathrm{CNT})$. The higher dispersion obtained on $\mathrm{Ru} / \mathrm{CNT}$ compared to Pd/CNT can be attributed to the higher energy of the $\mathrm{Ru}-\mathrm{C}$ bond $(4.43 \mathrm{eV}$ ) compared to the Pd-C bond (1.90 eV) [37].

As far as metallic particle location is concerned (exohedral $v s$ endohedral grafting), the nature of the support as well as the impregnation procedure should favor exohedral particle grafting. Indeed, for N-CNTs, their structure (absence of open inner cavity) precludes any endohedral grafting. For CNTs, the absence of oxidative treatment on purified CNTs (for example with $\mathrm{HNO}_{3}$ ) that allows CNT opening is not favorable to metallic particle grafting in the inner cavity of CNTs [38].

\subsection{Decomposition of isopropyl alcohol on CNTs and N-CNTs}

The isopropanol conversion was performed over these systems in order to evaluate the influence of nitrogen and/or metallic function on the acid-base properties of the catalysts. It is known that the results obtained in the acid characterization of solids using static methods, such as $\mathrm{NH}_{3}$-TPD and adsorption of basic probe molecules (pyridine, deuterated acetonitrile) coupled with IR spectroscopy, are in agreement with those achieved in dynamic studies. A good illustration of that is the conversion of IPA, where the most active catalysts are those that exhibit high acidity. For activated carbon, acidic carbons exhibit higher steady state conversions of IPA than basic carbons [39]. Carbon oxidation in liquid or gas phase, introduces carboxylic groups on its surface and leads to an increase of the catalytic activity, which is dominated by the dehydration process of the alcohol $[40,41]$. Activated carbon modified by $\mathrm{NH}_{3}$ results in a decrease of the catalytic activity and a significant
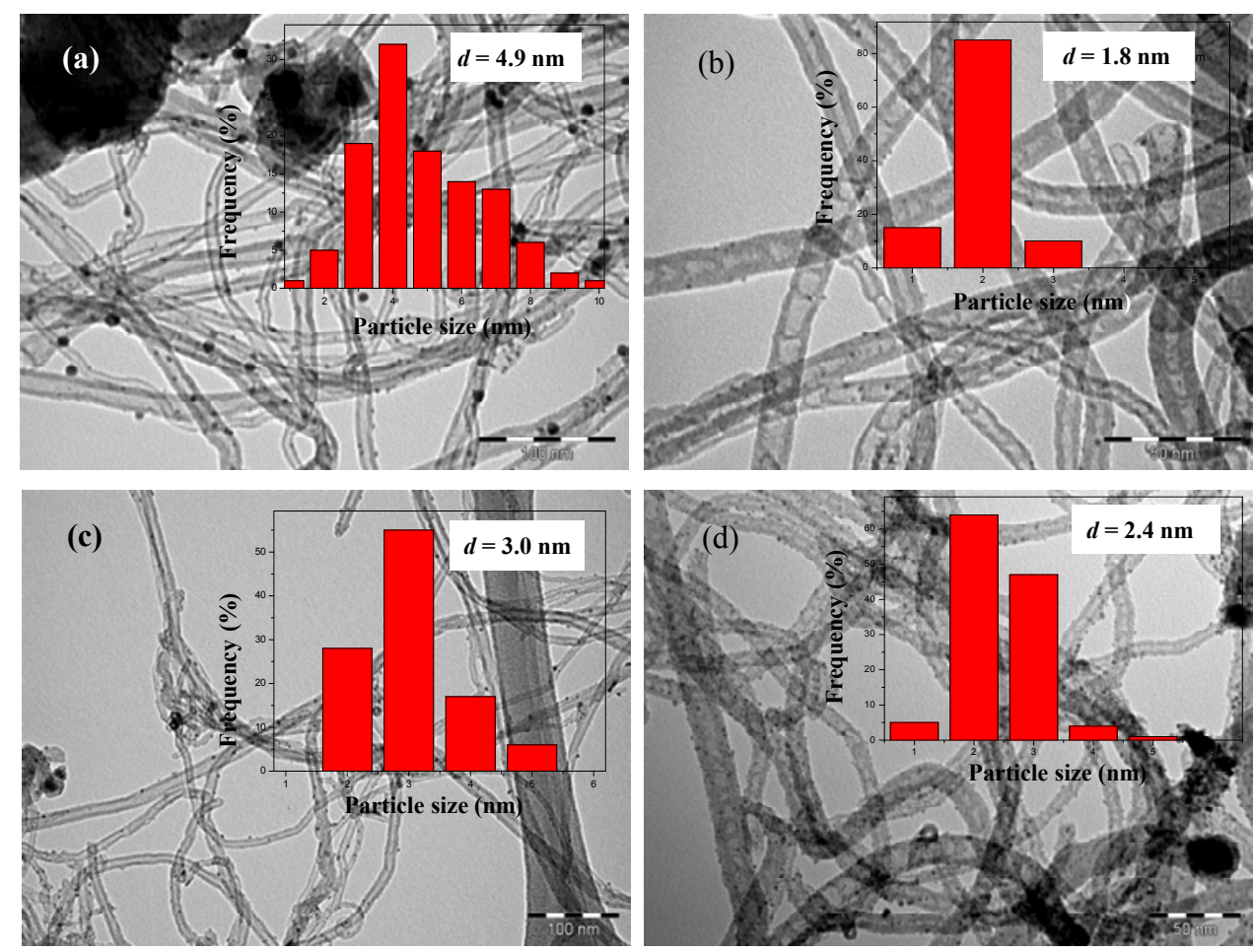

Fig. 3. TEM micrographs and particle size distributions of the 2 wt\% catalysts. (a) Pd/CNT; (b) Pd-N-CNT; (c) Ru/CNT; (d) Ru/N-CNT. 
increase of the IPA dehydrogenation [40].

The results presented in Figs. 4 and 5 show clearly the effect of the modification of CNTs by nitrogen. Figure 4 displays the evolution of isopropanol conversion and acetone yield versus time on stream at $210^{\circ} \mathrm{C}$ on CNTs, which bears very few functional groups. Experiments were conducted either in the absence $\left(\mathrm{N}_{2}\right)$ or in the presence of oxygen (air) in the reaction mixture. It should be noted that the presence of oxygen contributed to the exaltation the basic properties of the catalysts [13]. Dehydration products are totally absent in the case of non-modified CNTs, while the acetone production is enhanced reflecting the basic character of this material. Furthermore, the basic character of this catalyst is improved by oxygen addition in the reaction mixture. Although, there is a general agreement about the type of surface functionalities that determines the acidic character of a carbon material, the nature of carbon basic surfaces remains controversial and open to investigations [42]. Generally speaking, oxygen-containing functionalities (i.e., chromene, pyrone, ketones, quinones) and non-heteroatomic Lewis base sites, characterized by regions of electron density on the carbon basal planes govern carbon basicity $[43,44]$. In addition, air oxidation yields carbons possessing a less acidic surface and consequently, more easily distinguishable ampho-

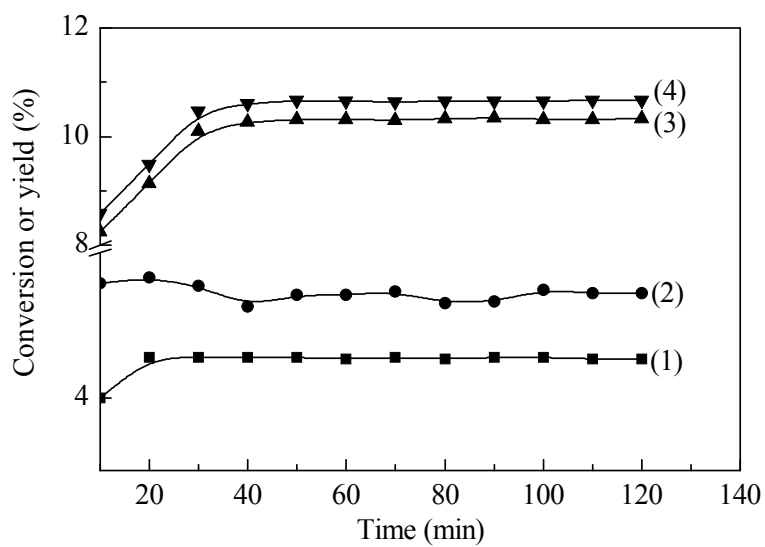

Fig. 4. Catalytic activity of CNTs versus time at $210^{\circ} \mathrm{C}$. Acetone Yield (1), IPA conversion (2) in absence of air; acetone yield (3) and IPA conversion (4) in presence of air.

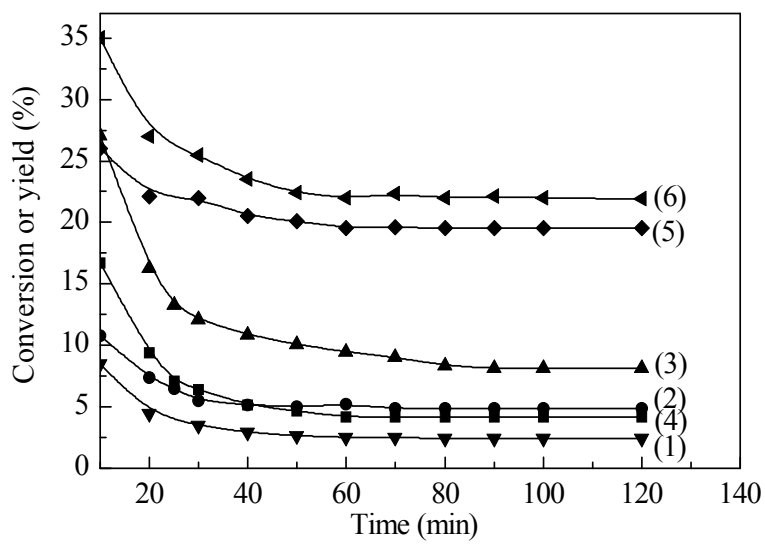

Fig. 5. Catalytic activity of N-CNTs versus time at $210^{\circ} \mathrm{C}$. Propene yield (1), acetone yield (2), and IPA conversion (3) in absence of air; propene yield (4), acetone yield (5), and IPA conversion (6) in presence of air. teric properties than those of carbons oxidized with nitric acid. It has been demonstrated that oxidation of activated carbon in the gas phase increases mainly the concentration of hydroxyl and carbonyl surface groups[44]. Oxidation of carbons with hot air results in a greater proportion of relatively weak acidic surface functional groups (i.e., phenolic) [45].

In contrast to CNTs, N-CNTs are active in both dehydration and dehydrogenation (Fig. 5). We achieved at steady state under nitrogen a conversion of $8.3 \%$. The formation of acetone and that of propene increased significantly in the presence of oxygen. The introduction of nitrogen changed both the acidic and basic properties. The dehydrogenation activity involves basic or redox sites in the presence of oxygen. It should be noted that the influence of the nitrogen content on the acid-base properties has been studied in the case of oxides and phosphates. The literature reported several investigations of oxynitrides aluminophosphates in different reactions (AlPON) [46-50]. Increasing the $\mathrm{N}$ content results in a reduction of the acidity and in an increase of the basic character $[49,50]$. The appearance of the dehydration activity after modification is due to the appearance of basic sites that participate in propene production. This is corroborated by the absence of any dehydration activity over CNTs in the selected operating conditions.

Figure 6 shows the evolution of the dehydrogenation activity over the CNTs and N-CNTs catalysts versus reaction temperature in absence and presence of oxygen in the reaction mixture. The acetone yield is enhanced by CNT nitrogen doping, and remarkably improved by the presence of oxygen. Furthermore, Fig. 7 displays the variations of the dehydration activity of N-CNTs versus the temperature, in the absence and in presence of oxygen in the reaction mixture.

Despite the low activity achieved, the role of CNTs doping with $\mathrm{N}$ is clearly revealed by the dehydration reaction, which is almost nonexistent in the case of pure CNTs. This effect can be assigned either to the appearance of new acid sites, or to a change in the mechanism of the reaction and a participation of new basic sites created by the introduction of nitrogen. As shown by XPS analyses there are four types of nitrogen over the N-CNTs (29\% pyridinic nitrogen, 31\% of pyrrolic nitrogen, $12 \%$ of quaternary nitrogen, and $28 \%$ of nitrogen oxides). The

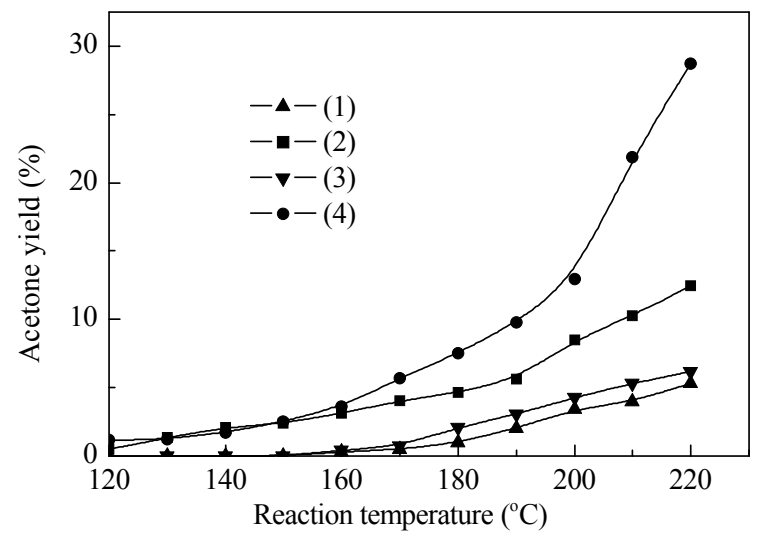

Fig. 6. Acetone yield versus reaction temperature over the CNTs catalysts in absence (1) and presence (2) of air; and over N-CNTs in absence (3) and presence (4) of air. 


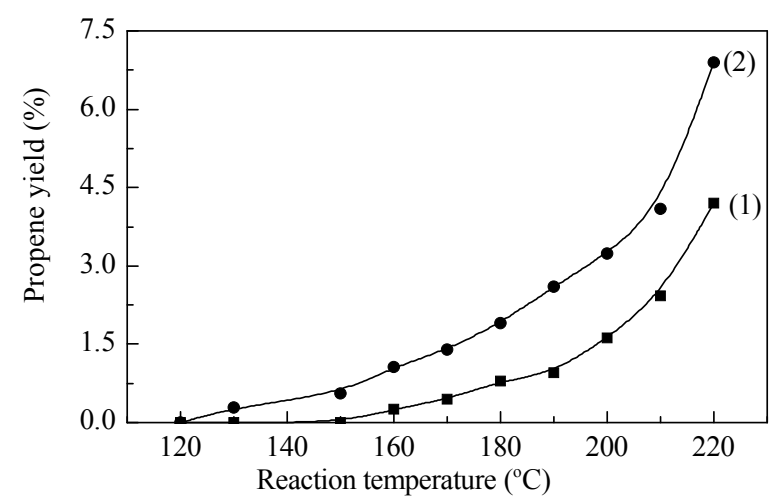

Fig. 7. Propene yield versus reaction temperature over N-CNTs catalysts in the absence (1) and presence (2) of air.

relative abundance and the chemical environment of these $\mathrm{N}$-containing groups is expected to determine the nanotube acid/base properties. Therefore, it is imperative to understand the electron donor/acceptor properties of these groups. Of these four types, the $\mathrm{sp}^{2}$ hybridized quaternary $\mathrm{N}$, substituting a carbon atom of the graphitic matrix, is under-coordinated and contributes with one electron to the conjugated $\pi$ system of the aromatic carbon matrix. From this results a delocalization of the electrons of the nitrogen atoms. Subsequently, removing an electron from this nitrogen, i.e. the uptake of $\mathrm{H}^{+}$by the nitrogen atom, will decrease the aromaticity of the system, which is energetically unfavorable. These nitrogens are not expected to display any basic behavior, and the quaternary nitrogen does not contribute to the basicity of the N-CNTs. The $\mathrm{sp}^{3}$ hybridized nitrogen atom in pyrrole is also part of an aromatic network. Protonation of the nitrogen atom requires electron donation to the $\mathrm{H}^{+}$ion, and results in a loss of aromaticity of the fivefold ring, which is energetically not favorable. Therefore, pyrrole will have an acidic character, as was also experimentally established [51]. The $\mathrm{N}-\mathrm{O}$ species, essentially being an oxidized form of pyridinic $\mathrm{N}$, have been reported to present an acidic character [52]. $\mathrm{p} K$ a values below 3 were found for pyridine $\mathrm{N}$-oxides and comparable compounds, determined from protonation experiments. With its electron pair, pyridinic nitrogen can act as a Lewis and/or a Brønsted base and thus can interact with a proton. Therefore, of all the N-types groups, only the pyridinic one is expected to present a basic character. Nevertheless, the presence of amine species cannot be ruled out. Several authors reported on amine species found in nitrogen incorporated in carbon by XPS analysis with a binding energy around $399.4 \mathrm{eV}$ [53]. With XPS however, the amine peak is difficult to distinguish from the adjacent overlapping peaks, viz. pyridinic $\mathrm{N}$ and pyrrolic $\mathrm{N}$.

As far as the presence of air is concerned, it induces a decrease of the selectivity of the N-CNTs towards propene and an increase of acetone selectivity. Such a phenomenon has already been reported for acidic carbon catalysts, for which in the absence of oxygen, the catalysts dehydrate isopropanol to propene. In the presence of oxygen, the acidic carbons show higher conversion values and part of the isopropanol suffers oxidative dehydrogenation yielding acetone as well as propene, although at high isopropanol steady state conversions only propene is
Table 2

Activation energies of the catalysts.

\begin{tabular}{|c|c|c|c|c|c|}
\hline \multirow{2}{*}{ Catalyst } & \multirow{2}{*}{ Gas } & \multicolumn{2}{|c|}{$E_{\mathrm{a}}\left(\mathrm{kJ} \mathrm{mol}^{-1}\right)$} & \multicolumn{2}{|c|}{ TOF $\left(\mathrm{s}^{-1}\right)$} \\
\hline & & Dehydrogenation & Dehydration & Acetone & Propene \\
\hline$\overline{\text { CNTs }}$ & $\mathrm{N}_{2}$ & 104.0 & - & & \\
\hline $\mathrm{N}$-CNTs & $\mathrm{N}_{2}$ & 98.7 & 79.9 & & \\
\hline CNTs & air & 42.7 & - & & \\
\hline $\mathrm{N}$-CNTs & air & 60.2 & 56.5 & & \\
\hline $\mathrm{Pd} / \mathrm{CNTs}$ & $\mathrm{N}_{2}$ & 78.3 & - & 186 & \\
\hline $\mathrm{Pd} / \mathrm{N}-\mathrm{CNTs}$ & $\mathrm{N}_{2}$ & 77.08 & - & 380 & \\
\hline $\mathrm{Pd} / \mathrm{CNTs}$ & air & 44.2 & - & 443 & \\
\hline $\mathrm{Pd} / \mathrm{N}-\mathrm{CNTs}$ & air & 104.5 & - & 594 & \\
\hline $\mathrm{Ru} / \mathrm{CNTs}$ & $\mathrm{N}_{2}$ & 99.34 & 52.4 & 36 & 8 \\
\hline $\mathrm{Ru} / \mathrm{N}-\mathrm{CNTs}$ & $\mathrm{N}_{2}$ & 63.2 & - & 97 & \\
\hline $\mathrm{Ru} / \mathrm{CNTs}$ & air & 44.9 & - & 34 & \\
\hline $\mathrm{Ru} / \mathrm{N}-\mathrm{CNTs}$ & air & 73.8 & - & 101 & \\
\hline
\end{tabular}

obtained [39].

The associated apparent activation energies are reported in Table 2.

It might be noted that the values obtained are in good agreement with the results by other authors [54].

\subsection{Decomposition of isopropyl alcohol over supported catalysts}

The Ru and Pd loading on CNTs and N-CNTs modifies their catalytic behavior. A promoting effect is particularly obvious as regards to the formation of acetone. Figure 8 shows the variation of the acetone production versus time on the $\mathrm{Pd}$ and $\mathrm{Ru}$ supported on CNTs and N-CNTs. Activity is measured at $210{ }^{\circ} \mathrm{C}$ in the absence of air in the reaction mixture.

On all the supports examined, the incorporation of palladium resulted in a much higher activity (Table 2). The presence of N-CNTs plays an important role in the enhancement of acetone production with the two metals used. The TOFs obtained with the Pd/N-CNTs are comparable with the higher ones reported up to day in the literature [55].

However, it is also noteworthy that the selectivity changes depending on the metal and the support. In the case of Pd, whatever the support is, the acetone selectivity reaches $100 \%$. In the case of $\mathrm{Ru}$, in the presence CNTs, selectivity to acetone

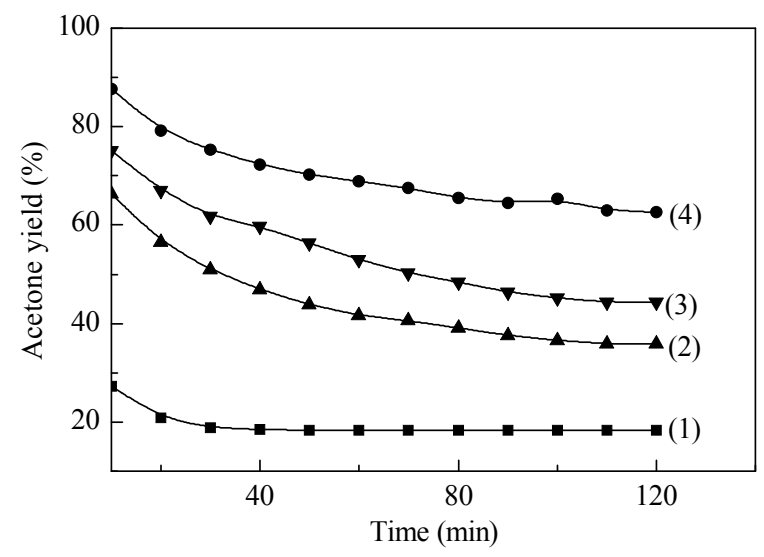

Fig. 8. Acetone yield versus time in the absence of air at $210^{\circ} \mathrm{C}$ over $\mathrm{Ru} / \mathrm{CNTs}(1), \mathrm{Pd} / \mathrm{CNTs}$ (2), Ru/N-CNTs (3), and Pd/N-CNTs (4). 


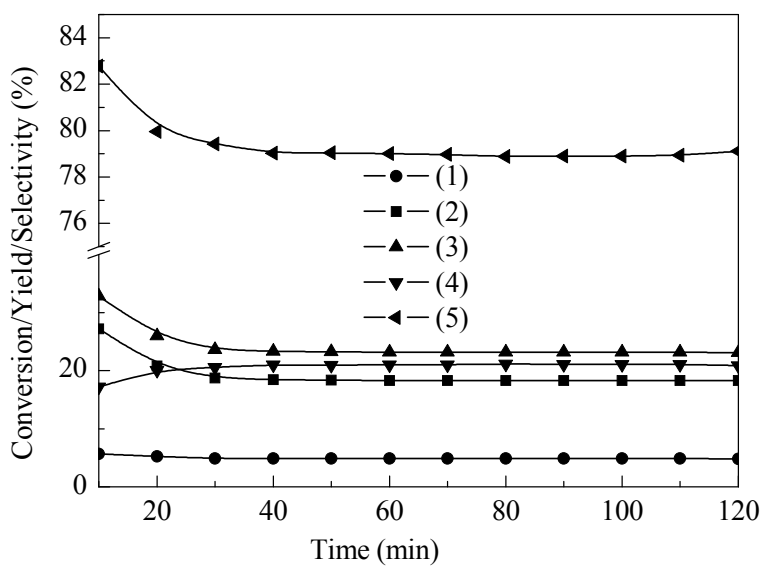

Fig. 9. Propene yield (1), acetone yield (2), IPA conversion (3), propene selectivity (4), and acetone selectivity (5), over Ru/N-CNTs versus time in absence of oxygen at $210^{\circ} \mathrm{C}$.

was lower because of the formation of propene and propane (about 1\%) (Fig. 9). The most reasonable explanation is the appearance of acid sites of different strength due to the presence of Ru. In view of their small particle size, it seems realistic to consider that Ru nanoparticles are oxidized at least on their surface, and that Lewis $\mathrm{RuO}_{2}$ or Brönsted/Lewis $\mathrm{Ru}-\mathrm{OH}$ sites are present on the Ru catalysts [56]. Palladium, which has a much higher redox potential $\left(E^{0}=0.951 \mathrm{~V} \mathrm{Pd}^{2+} / \mathrm{Pd}^{0}, E^{0}=0.455\right.$ $\left.\mathrm{V} \mathrm{Ru}^{2+} / \mathrm{Ru}^{0}, E^{0}=0.951 \mathrm{~V} \mathrm{Pd}^{2+} / \mathrm{Pd}^{0}\right)$ is present mainly in the metallic state on the carbon supports. Spontaneous oxidation of $\mathrm{Ru} / \mathrm{CNT}$ catalyst in air has been recently reported by some of us [57]. The propene formation on Ru catalysts can be attributed to the presence of Brönsted-type acid centers ( $\mathrm{Ru}-\mathrm{OH})$. Indeed, it was shown that a higher surface acidity, due to Brönsted-type acid centers, favors the dehydration of IPA [58]. Propane is generally obtained with catalysts bearing Brönsted sites [59].

Figure 10 displays the yields obtained with the same Pd and Ru catalysts loaded on CNTs and N-CNTs in the presence of air in the reaction mixture at $115{ }^{\circ} \mathrm{C}$. We notice that the Pd-containing catalysts are very stable under these operating condi-

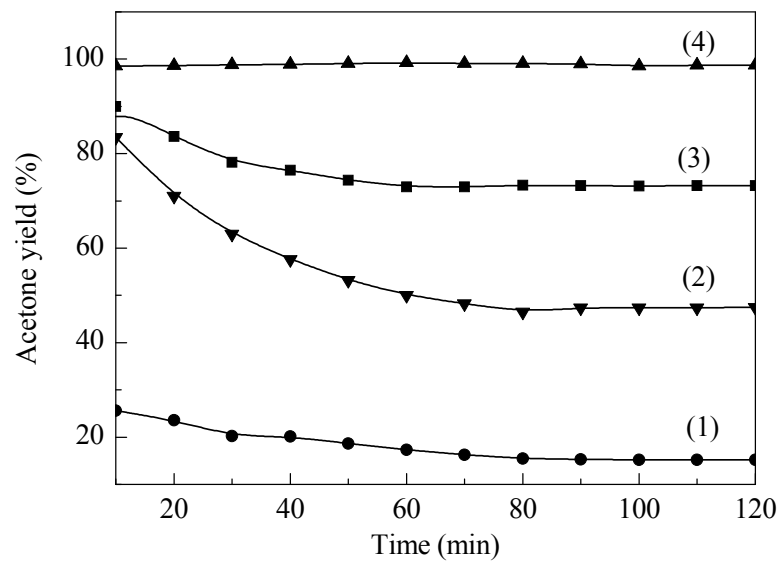

Fig. 10. Acetone yield variation versus time on stream in the presence of air at $115{ }^{\circ} \mathrm{C}$ over Ru/CNTs (1), Ru/N-CNTs (2), Pd/CNTs (3), and Pd/N-CNTs (4).

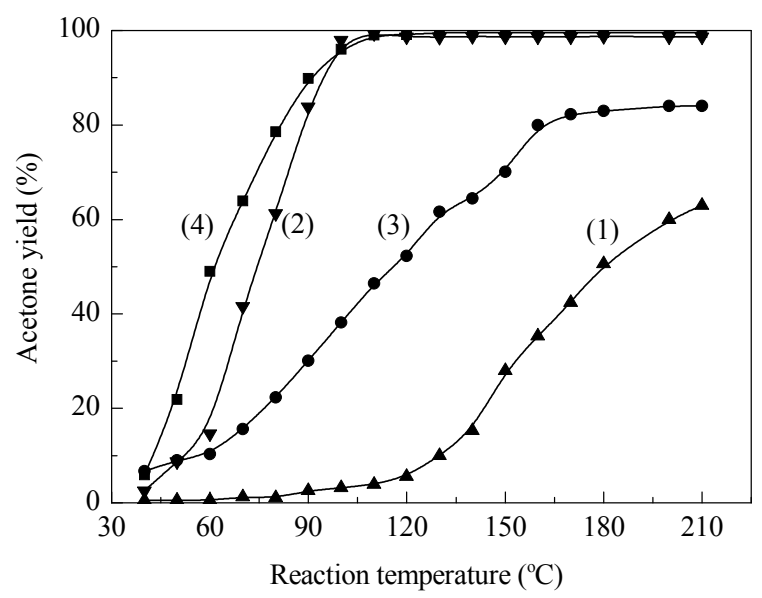

Fig. 11. Acetone yield over Pd/CNTs catalysts versus reaction temperature in absence (1) and presence (2) of air, and over Pd/N-CNTs in absence (3) and in presence (4) of air.

tions, and more active than the Ru ones. It should also be noted

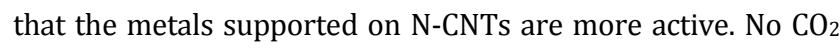
production was observed under the experimental conditions used. The results confirm the basicity of the catalysts prepared, which appears more pronounced in the presence of oxygen. The metal sites activate the oxygen and favor the formation of negatively charged oxygen species [60].

As already reported above, the best catalytic performances were obtained with the catalysts supported on N-CNTs. This trend is well confirmed by changes in activity versus the reaction temperature. Figure 11 shows the evolution of the catalytic activity of Pd catalysts supported on CNTs and N-CNTs in the presence and absence of oxygen as a function of temperature. We note that in the absence of air, the nature of the support influences the activity, which is more important for the Pd supported on N-CNTs. In the presence of air in the reaction mixture, the activity does not seem to be related to the nature of the support.

Similarly, Fig. 12 shows the variations of the catalytic activity of the Ru supported on CNTs and N-CNTs versus the reaction temperature in the presence and absence of air in the reaction

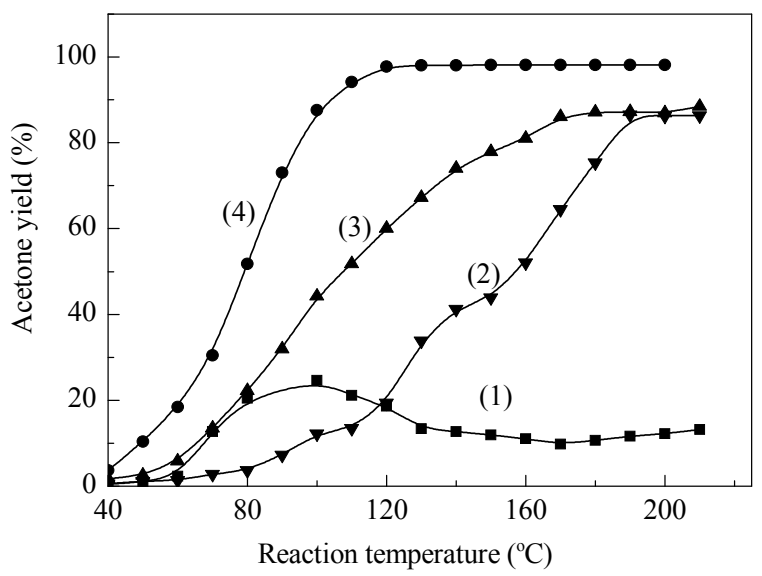

Fig. 12. Acetone yield versus reaction temperature, over $\mathrm{Ru} / \mathrm{CNTs}$ catalysts, in absence (1) and presence (2) of air, and over Ru/N-CNTs in absence (3) and presence (4) of air. 


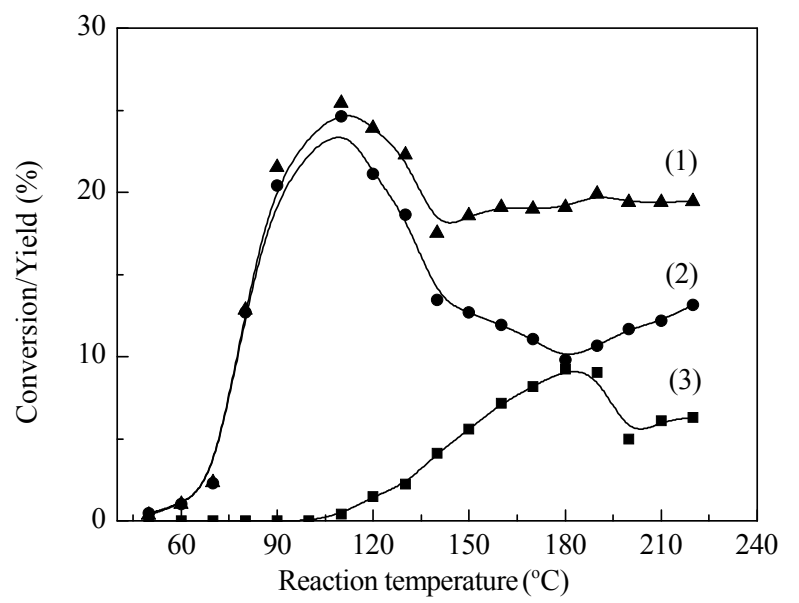

Fig. 13. Isopropanol conversion (1), propene yield (2), and acetone yield (3) variation versus reaction temperature in absence of air.

mixture. Unlike the case of Pd catalysts, the Ru catalyst activity depends on the nature of the support in the presence of air. Thus, the Ru/N-CNTs catalyst is more active than the Ru/CNTs catalyst. However, the most remarkable result is that obtained with $\mathrm{Ru} / \mathrm{CNT}$ s in the absence of air.

As it was mentioned earlier, this is the only catalyst that led to a significant amount of propene (Fig. 13).

Note that increasing the dehydrating activity corresponds to the decrease in the dehydrogenation activity. In this case, we can assume that the two reactions have a common intermediate or involve at least one common type of sites [61].

\section{Conclusions}

CNTs and N-CNTs have been prepared by CVD and used as support for $\mathrm{Pd}$ and $\mathrm{Ru}$ deposition. Higher dispersions were obtained on the N-doped nanotubes. N-CNTs are more active than the relatively inert CNTs for IPA conversion. While CNTs produce only acetone (basic sites), N-CNTs produce both acetone and propene (basic and acidic sites). The $\mathrm{N}$ doping induces the appearance of redox properties, which appear when oxygen is present in the reaction mixture. The dehydrogenation of IPA over N-doped CNTs and CNT supported Pd and Ru catalysts revealed that $\mathrm{Pd}$ was much more active than $\mathrm{Ru}$, and $\mathrm{Pd}$ catalysts were selective towards acetone when supported on the two kinds of support. In contrast, $\mathrm{Ru}$ supported on similar supports lead to dehydration and dehydrogenation products, mainly in the presence of nitrogen as carrier gas. The use of $\mathrm{Pd} / \mathrm{N}$-CNTs catalyst allows to reach turnover frequencies as high as $600 \mathrm{~s}^{-1}$ with $100 \%$ selectivity towards acetone formation.

\section{Acknowledgments}

The 'French-Moroccan Laboratory of Molecular Chemistry' (LIA/LCMMF) and the CNRST are gratefully acknowledged for the funding provided to this work. The authors wish also to thank Mrs. Laure Vendier (CEMES, Toulouse, France) for technical assistance for EELS measurements.

\section{References}

[1] Lauron-Pernot H. Catal Rev-Sci Eng, 2006, 48: 315

[2] Turek W, Krowiak A. Appl Catal A, 2012, 417-418: 102

[3] Gervasini A, Auroux A.J Catal, 1991, 131: 190

[4] Rioux R M, Vannice M A. J Catal, 2005, 233: 147

[5] Moreno-Castilla C, Maldonado-Hódar F J, Rivera-Utrilla J, Rodríguez-Castellón E. Appl Catal A, 1999, 183: 345

[6] Moreno-Castilla C, Carrasco-Marín F, Parejo-Pérez C, López Ramó M V. Carbon, 2001, 39: 869

[7] Bedia J, Rosas J M, Márquez J, Rodríguez-Mirasol J, Cordero T. Carbon, 2009, 47: 286

[8] Carrasco-Marín F, Mueden A, Moreno-Castilla C. J Phys Chem B, 1998, 102: 9239

[9] Al-Daous M A, Manda A A, Hattori H. J Mol Catal A, 2012, 363-364: 512

[10] Ogo S, Onda A, Yanagisawa K. Appl Catal A, 2008, 348: 129

[11] Campelo J M, Garcia A, Herencia J F, Luna D, Marinas J M, Romero A A. J Catal, 1995, 151: 307

[12] Gervasini A, Fenyvesi J, Auroux A. Catal Lett, 1997, 43: 219

[13] Yasu-eda T, Kitamura S, Ikenaga N, Miyake T, Suzuki T. J Mol Catal A, 2010, 323: 7

[14] Mears D E, Boudart M. AIChE J, 1966, 12: 313

\section{Graphical Abstract}

Chin. J. Catal., 2014, 35: 970-978 doi: 10.1016/S1872-2067(14)60121-2

Conversion of isopropyl alcohol over Ru and Pd loaded $\mathbf{N}$-doped carbon nanotubes

Anas Benyounes, Mohamed Kacimi*, Mahfoud Ziyad, Philippe Serp*

Toulouse University, France;

University of Mohammed V-Agdal, Morocco;

Hassan II Academy of Science and Technology, Morocco

The introduction of nitrogen in the carbon framework changes the acido-basic properties of the material. The Pd catalysts on nitrogen-doped nanotubes allows reaching turnover frequencies of $600 \mathrm{~s}^{-1}$ with $100 \%$ selectivity towards acetone formation.

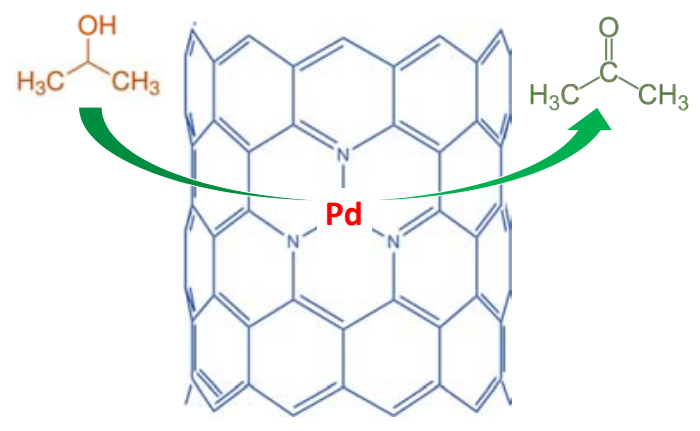


[15] Rioux R M, Vannice M A. J Catal, 2003, 216: 362

[16] Pepe F, Angeletti C, De Rossi S, Jacono M L. J Catal, 1985, 91: 69

[17] Alvarez-Merino M A, Carrasco-Marín F, Fierro J L G, Moreno-Castilla C.J Catal, 2000, 192: 363

[18] Moreno-Castilla C, Pérez-Cadenas A F, Maldonado-Hódar F J, Carrasco-Marín F, Fierro J L G. Carbon, 2003, 41: 1157

[19] Zawadzki J, Wiśniewski M, Weber J, Heintz O, Azambre B. Carbon, 2001, 39: 187

[20] Han Y, Shen J, Chen Y. Appl Catal A, 2001, 205: 79

[21] Wang H, Maiyalagan T, Wang X. ACS Catal, 2012, 2: 781

[22] Liu G, Li X, Lee J-W, Popov, B N. Catal Sci Technol, 2011, 1: 207

[23] Boehm, H P, Catalytic Properties of Nitrogen-Containing Carbons. In: Serp P, Figueiredo J L eds. Carbon Materials for Catalysis. New York: John Wiley \& Sons, 2008. 219

[24] Koós A A, Dowling M D, Jurkschat K, Crossley A, Grobert N. Carbon $2009,47: 30$

[25] Florea I, Ersen O, Arenal R, Ihiawakrim D, Messaoudi C, Chizari K Janowska I, Pham-Huu C. J Am Chem Soc, 2012, 134: 9672

[26] O'Byrne J P, Li Z, Jones S L T, Fleming P G, Larsson J A, Morris M A, Holmes J D. ChemPhysChem, 2011, 12: 2995

[27] Yadav R M, Dobal P S, Shripathi T, Katiyar R S, Srivastava O N. Nanoscale Res Lett, 2009, 4: 197

[28] He M, Zhou S, Zhang J, Liu Z, Robinson C. J Phys Chem B, 2005, 109: 9275

[29] Geng D, Yang S, Zhang Y, Yang J, Liu J, Li R, Sham T-K, Sun X, Ye S Knights S. Appl Surf Sci, 2011, 257: 9193

[30] Dresselhaus M S, Dresselhaus G, Saito R, Jorio A. Phys Rep, 2005, 409: 47

[31] Bulusheva L G, Okotrub A V, Kinloch I A, Asanov I P, Kurenya A G, Kudashov A G, Chen X, Song H. Phys Status Solidi B, 2008, 245: 1971

[32] Sharifi T, Nitze F, Barzegar H R, Tai C-W, Mazurkiewicz M, Malolepszy A, Stobinski L, Wågberg T. Carbon, 2012, 50: 3535

[33] Mabena L F, Sinha Ray S, Mhlanga S D, Coville N J. Appl Nanosci, 2011, 1: 67

[34] Vinayan B P, Ramaprabhu S. Nanoscale, 2013, 5: 5109

[35] Chen Y, Wang J, Liu H, Banis M N, Li R, Sun X, Sham T K, Ye S, Knights S. J Phys Chem C, 2011, 115: 3769

[36] Abate S, Freni M, Arrigo R, Schuster M E, Perathoner S, Centi G. ChemCatChem, 2013, 5: 1899

[37] Nakada K, Ishii A. Solid State Commun, 2011, 151: 13
[38] Trang Nguyen T, Serp P. ChemCatChem, 2013, 5: 3595

[39] Bedia J, Rosas J M, Vera D, Rodriguez-Mirasol J, Cordero T. Catal Today, 2010, 158: 89

[40] Jasinska E, Krzyzynska B, Kozlowski M. Catal Lett, 2008, 125: 145

[41] Ferens A R, Weinstein R D, Giuliano R, Hull J A. Carbon, 2012, 50: 192

[42] Fuente E, Menéndez J A, Suárez D, Montes-Morán M A. Langmuir, 2003, 19: 3505

[43] Montes-Morán M A, Suárez D, Menéndez J A, Fuente E. Carbon, 2004, 42: 1219

[44] Shafeeyan M S, Daud W M A W, Houshmand A, Shamiri A. J Anal Appl Pyrolysis, 2010, 89: 143

[45] Strelko Jr V, J Malik D, Streat M. Carbon, 2002, 40:95

[46] Wiame H, Cellier C, Grange P. J Catal, 2000, 190: 406

[47] Busca G, Lorenzelli V, Porcile G, Baraton M I, Quintard P, Marchand R. Mater Chem Phys, 1986, 14: 123

[48] Lednor P W, De Ruiter R. J Chem Soc, Chem Commun,1991: 1625

[49] Massinon A, Odriozola J A, Bastians P, Conanec R, Marchand R, Laurent Y, Grange P. Appl Catal A, 2013, 137: 9

[50] Grange P, Bastians P, Conanec R, Marchand R, Laurent Y. Appl Catal A,1994, 114: L191

[51] Shimoyama I, Wu G, SekiguchiT, BabaY. J Electron Spectrosc, 2001, 114-116: 841

[52] Balon M, Carmona M C, Munoz M A, Hidalgo J. Tetrahedron, 1989, 45: 7501

[53] Kundu S, Xia W, Busser W, Becker M, Schmidt D A, Havenith M, Muhler M. Phys Chem Chem Phys, 2010, 12: 4351

[54] Povarova E I, Pylinina A I, Mikhalenko I I. Russ J Phys Chem A, 2012, 86: 935

[55] Kulkarni D, Wachs I E. Appl Catal A, 2002, 237: 121

[56] Oishi T, Yamaguchi K, MizunoN. Top Catal, 2010, 53: 479

[57] Machado B F, Oubenali M, Axet M R, Trang Nguyen T T, Tunckol M, Girleanu M, Ersen O, Gerber I C, Serp P.J Catal, 2014, 309: 185

[58] Pérez-Cadenas A F, Moreno-Castilla C, Maldonado-HódarF J, Fierro J L G. J Catal, 2003, 217: 30

[59] Rouimi M, Ziyad M, Leglise J. Phosphorus ResBull, 1999, 10: 418

[60] Meira D M, Cortez G G, Monteiro W R, Rodrigues J A J. Brazi J Chem Eng, 2006, 23: 351

[61] New Solid Acids and Bases Their Catalytic Properties. Edited by Tanabe K, Misono M, Ono Y, Hattori H. Stud Surf Sci Catal, 1989, 51: 1 